\title{
Histopathological Changes of the Thyroid and Parathyroid Glands in HIV-Infected Patients
}

\author{
Rabia Cherqaoui, ${ }^{1}$ K. M. Mohamed Shakir, ${ }^{2}$ Babak Shokrani, ${ }^{3}$ Sujay Madduri, ${ }^{4}$ \\ Faria Farhat, ${ }^{5}$ and Vinod Mody ${ }^{5}$ \\ ${ }^{1}$ Howard University Hospital, 2041 Georgia Avenue NW, Washington, DC 20060, USA \\ ${ }^{2}$ Department of Endocrinology, National Naval Medical Center, 8901 Wisconsin Avenue, Bethesda, MD 20889, USA \\ ${ }^{3}$ Department of Pathology, 2041 Georgia Avenue NW, Washington, DC 20060, USA \\ ${ }^{4}$ Division of Endocrinology and Metabolism, 2041 Georgia Avenue NW, Washington, DC 20060, USA \\ ${ }^{5}$ Division of Infectious Disease, Department of Internal Medicine, Howard University Hospital, 2041 Georgia Avenue NW, \\ Washington, DC 20060, USA
}

Correspondence should be addressed to Rabia Cherqaoui; cherqaoui_rabi@yahoo.com

Received 6 September 2013; Revised 15 November 2013; Accepted 18 November 2013; Published 22 January 2014

Academic Editor: B. Stack

Copyright (c) 2014 Rabia Cherqaoui et al. This is an open access article distributed under the Creative Commons Attribution License, which permits unrestricted use, distribution, and reproduction in any medium, provided the original work is properly cited.

Objective. To study histopathology of the thyroid and parathyroid glands in HIV-infected African Americans in the United States. Methods. A retrospective review of 102 autopsy cases done by the Department of Pathology at Howard University Hospital from 1980 through 2007 was conducted. The histopathological findings of the thyroid and parathyroid glands were reviewed, both macroscopically and microscopically. A control group of autopsy patients with chronic non-HIV diseases was examined. Results. There were 71 males (70\%) and 31 females (30\%) with an average age of 38 years (range: $20-71 \mathrm{y}$ ). Thirteen patients with abnormal thyroid findings were identified. Interstitial fibrosis was the most common histological finding (4.9\%), followed by thyroid hyperplasia (1.9\%). Infectious disease affecting the thyroid gland was limited to $2.9 \%$ and consisted of mycobacterium tuberculosis, Cryptococcus neoformans, and cytomegalovirus. Kaposi sarcoma of the thyroid gland was present in only one case (0.9\%). Parathyroid hyperplasia was the most common histological change noted in the parathyroid glands. Comparing the histological findings of cases and controls, we found a similar involvement of the thyroid, with a greater prevalence of parathyroid hyperplasia in HIV patients. Conclusion. Thyroid and parathyroid abnormalities are uncommon findings in the HIV-infected African American population.

\section{Introduction}

Human immunodeficiency virus (HIV) and Acquired Immune Deficiency Syndrome (AIDS) are associated with multiple endocrine abnormalities [1]. Several investigators have studied the metabolic derangements and reported the functional abnormalities with specific endocrine glands [2]. There is however scant literature regarding histopathology of the thyroid and parathyroid glands in patients with HIV and AIDS, particularly in African Americans (AA). Nevertheless, extensive literature is available on serum biochemical thyroid functions and calcium fluctuations in these patients. Euthyroid sick syndrome, hypothyroidism, hypocalcemia, impaired parathyroid hormone secretion, and vitamin $\mathrm{D}$ deficiency appear to be common among the adult HIV-infected patients [3-5].

We postulated that the thyroid and parathyroid glands would be involved in AIDS patients as evidenced by functional abnormalities and derangements seen in these patients. Our study is the first retrospective report to describe the histopathology of the thyroid and parathyroid glands in HIVinfected AA patients in an inner city hospital in the United States.

\section{Materials and Methods}

A retrospective review of histopathology findings of the thyroid and parathyroid glands at autopsy was conducted 
at a tertiary care teaching hospital during the year 1980 through 2007. One hundred and two HIV-infected patients who died after admission to Howard University Hospital were identified. The study was reviewed and approved by the Institutional Review Board.

At the time of autopsy, thyroid and parathyroid glands were examined macroscopically and microscopically. Two transverse sections of the thyroid gland were routinely performed. If pathological lesions were noted, multiple sections were performed. Histopathological diagnosis was confirmed by two certified pathologists. Sections were stained with hematoxylin and eosin. Other stains included periodic acid Schiff, Grocott's methenamine silver and Ziehl-Neelsen stain as necessary.

The starting time of the study coincided with the introduction of Highly Active Antiretroviral Treatment (HAART); hence, no many patients were on HAART. Additionally, one third of patients reviewed died before initiation of HAART. We could retrieve a CD4 count only in $20.5 \%$ of patients. Incomplete adherence to the prescribed regimen was common, as self-reported by patients as well as evidenced by the number of HIV associated opportunistic infections these patients harbored. We compared the histopathological findings to a control-group which included patients without HIV infection ( 31 females and 44 males) who died at the hospital from other causes. Chi-square test was used to calculate the significance of these observations.

\section{Results}

3.1. Patient Characteristics. One hundred and two autopsy cases were reviewed in this study. There were 71 males $(70 \%)$ and 31 females (30\%) with an average age of 38 (range: $20-$ 71 years). The mean time from HIV diagnosis to death was 53 months (range: 1-144 months). Most of the patients had AIDS, as suggested by the number of opportunistic infections they had (\% patients had AIDS defining illnesses). CD4 lymphocyte count was documented in $20.5 \%$ of patients with a median CD4 count of 50 cells/ $\mu$ L. Eighty patients $(78.4 \%)$ did not receive Pneumocystis jiroveci prophylaxis. Thirtyfour $(33 \%)$ of patients were from the pre-HAART period (1980-1990). Fourteen patients were on HAART. Our series included 40 patients with intravenous drug abuse (39.2\%), 23 (22.5\%) with heterosexual risk, 23 (22.5\%) with homosexual or bisexual risk, and 56 (55\%) with undocumented sexual preference. It is to be noted that these high risk behavior patterns were not mutually exclusive.

A control group for thyroid histopathologic examination was obtained in 75 non-HIV-infected patients. Comparing the histological findings of cases and controls, we found similar involvement of the thyroid, with greater prevalence of parathyroid hyperplasia in HIV patients.

3.2. Pathologic Findings. The thyroid gland weighed between 3 to $40 \mathrm{~g}$. Weights of parathyroid glands were not available. Thyroid gland findings are shown in Table 1 . Thirteen patients (7 males and 6 females) had abnormal histopathology of the thyroid gland. The mean age was 41 years, with a range
TABLE 1: Summary of thyroid gland findings in HIV-infected patients and controls.

\begin{tabular}{lccc}
\hline Thyroid* & $\begin{array}{c}\text { HIV-infected } \\
\text { patients N (\%) }\end{array}$ & $\begin{array}{c}\text { Non-HIV-infected } \\
\text { patients N (\%) }\end{array}$ & $P$ value \\
\hline $\begin{array}{l}\text { Normal } \\
\begin{array}{l}\text { Abnormal } \\
\text { (microscopic) }\end{array}\end{array}$ & $12(87.3)$ & $65(86.6)$ & $\mathrm{ns}$ \\
$\begin{array}{l}\text { Abnormal } \\
\text { (macroscopic) }\end{array}$ & $2(1.96)$ & $10(13.3)$ & 0.11 \\
\hline
\end{tabular}

${ }^{*}$ The numbers will not sum to $100 \%$ since the categories are not mutually exclusive.

TABLE 2: Summary of parathyroid glands findings in HIV-infected patients and controls.

\begin{tabular}{lccc}
\hline Parathyroids $^{* *}$ & $\begin{array}{c}\text { HIV-infected } \\
\text { patients N (\%) }\end{array}$ & $\begin{array}{c}\text { Non-HIV-infected } \\
\text { patients N (\%) }\end{array}$ & $P$ value \\
\hline $\begin{array}{l}\text { Normal } \\
\text { Abnormal } \\
\text { (microscopic) }\end{array}$ & $69(67.6)$ & $72(96)$ & ns \\
$\begin{array}{l}\text { Abnormal } \\
\text { (macroscopic) }\end{array}$ & $2(1.96)$ & $3(4)$ & 0.04 \\
\hline
\end{tabular}

${ }^{* *}$ The numbers will not sum to $100 \%$ since the categories are not mutually exclusive.

of 30-62 years. Seven of these patients had a history of intravenous drug abuse. The mean time from HIV diagnosis to death was 65.8 months ranging from 6 to 132 months. Only 4 of 13 patients had a CD 4 count available with a mean 64 , range of $0-200$. One patient in this group was receiving Pneumocystis jiroveci prophylaxis and 4 patients were on HAART. The mean body mass index (BMI) was $25 \mathrm{~kg} / \mathrm{m}^{2}$ with a range of $15-40 \mathrm{~kg} / \mathrm{m}^{2}$. The mean weight of the thyroid gland was 21.4 grams with a range of 3 to 32 grams.

The gross examination of the thyroid gland was unremarkable in 100 patients (98\%). One patient had a macroscopically nodular thyroid gland while another patient had an atrophic thyroid gland. The latter patient had both macroscopic (atrophy) and microscopic abnormalities (fibrosis) (Table 1). In the control group, the macroscopic histopathologic analysis of the thyroid revealed 68 patients $(90.6 \%)$ having a normal thyroid macroscopic examination (Table 1).

Histological diagnoses are summarized in Tables 3 and 4.

Interstitial fibrosis (Figure 1) was the most common histological finding identified in thyroid gland sections (4.9\%), followed by thyroid hyperplasia (1.9\%). Isolated mild interstitial fibrosis was found in 2 patients. Two patients had interstitial fibrosis associated with hyperplasia of the thyroid gland. One patient showed a moderate degree of fibrosis and atrophy of the thyroid gland. One case of colloid goiter and one case of thyroid adenoma were also identified at autopsy (Table 3).

Infections of the thyroid gland included cytomegalovirus (1 case), Mycobacterium tuberculosis (1 case), and Cryptococcus (1 case), (Figures 2 and 3 ). 


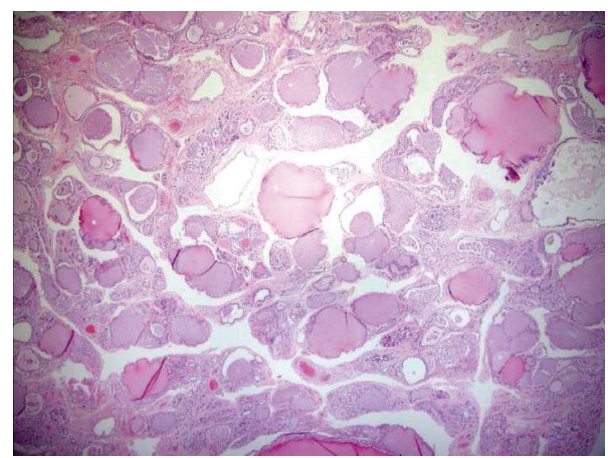

FIGURE 1: Microscopic section of the thyroid showing fibrosis of the interstitium (H\&E, 400x).

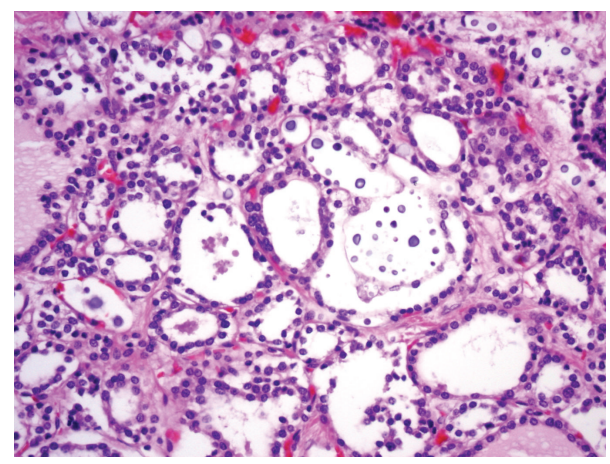

FIgURE 2: Microscopic section of the thyroid gland, (H\&E) showing Cryptococcus with variation in size $(400 \mathrm{x})$.

TABLE 3: Histopathological findings in thyroid gland.

\begin{tabular}{lcc}
\hline Histologic findings & $\begin{array}{c}\text { Frequency } \\
\text { HIV-infected } \\
\text { patients (\%) }\end{array}$ & $\begin{array}{c}\text { Frequency } \\
\text { Non-HIV-infected } \\
\text { patients (\%) }\end{array}$ \\
\hline $\begin{array}{l}\text { Nodular goiter } \\
\begin{array}{l}\text { Cryptococcal } \\
\text { infection }\end{array}\end{array}$ & $3(2.7 \%)$ & $6(8 \%)$ \\
$\begin{array}{l}\text { Mycobacterium } \\
\text { Tuberculosis }\end{array}$ & $1(0.9 \%)$ & $1(1.3 \%)$ \\
$\begin{array}{l}\text { Kaposi sarcoma } \\
\text { CMV infection }\end{array}$ & $1(0.9 \%)$ & $1(1.3 \%)$ \\
$\begin{array}{l}\text { Interstitial fibrosis } \\
\text { Lymphocytic }\end{array}$ & $1(0.9 \%)$ & 0 \\
thyroiditis & $5(4.9 \%)$ & 0 \\
Papillary carcinoma & 0 & $2(2.6 \%)$ \\
\hline
\end{tabular}

Furthermore, the most common systemic opportunistic infection in 13 of our patients with thyroid abnormalities was Mycobacterium avium complex infection (MAC) (38.4\%) followed by Candida albicans (Figures 4 and 5). In the remaining HIV-infected patients without thyroid abnormalities, the most frequent opportunistic infection was Pneumocystis jiroveci (32.5\%), followed equally by Candida and cytomegalovirus (19.1\%).

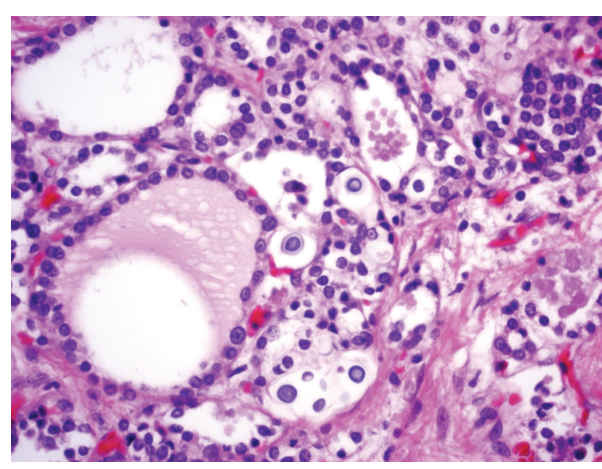

FIgURE 3: Microscopic section of the thyroid gland, (H\&E) showing Cryptococcus (600x).

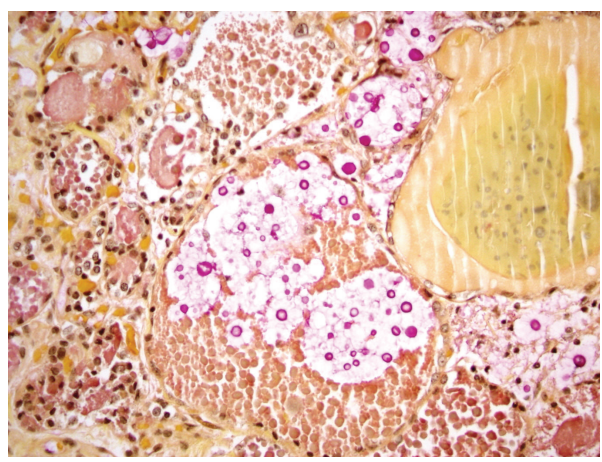

FIGURE 4: Microscopic section of the thyroid gland, mucin stain highlights yeast with thick capsule (400x).

TABLE 4: Histopathological findings in parathyroid glands.

\begin{tabular}{lcc}
\hline Histologic findings & $\begin{array}{c}\text { Frequency } \\
\text { HIV-infected } \\
\text { patients (\%) }\end{array}$ & $\begin{array}{c}\text { Frequency } \\
\text { Non-HIV-infected } \\
\text { patients (\%) }\end{array}$ \\
\hline $\begin{array}{l}\text { Parathyroid } \\
\text { hyperplasia }\end{array}$ & $23(22.5 \%)$ & $2(2.6 \%)$ \\
$\begin{array}{l}\text { Nodular oncocytic } \\
\text { hyperplasia }\end{array}$ & $3(2.9 \%)$ & 0 \\
CMV infection & $3(2.9 \%)$ & 0 \\
Fatty infiltration & $2(1.9 \%)$ & $1(1.3 \%)$ \\
Serous atrophy & $2(1.9 \%)$ & 0 \\
\hline
\end{tabular}

CMV: cytomegalovirus.

Parathyroid glands involvement was noted in 32.1\% of patients. Parathyroid hyperplasia was by far the most common histological finding accounting for $22.5 \%$ of cases followed by cytomegalovirus (CMV) infection of the parathyroid $(2.9 \%)$ and nodular oncocytic hyperplasia (2.9\%). Parathyroid hyperplasia was diagnosed if at least two of all four parathyroid glands were hyperplastic. Fatty infiltration $(1.9 \%)$ and serous atrophy $(1.9 \%)$ were also identified in the parathyroid glands (Table 4) (See Figures 6 and 7).

Most of these patients studied died of septic shock or respiratory failure (data not shown). 


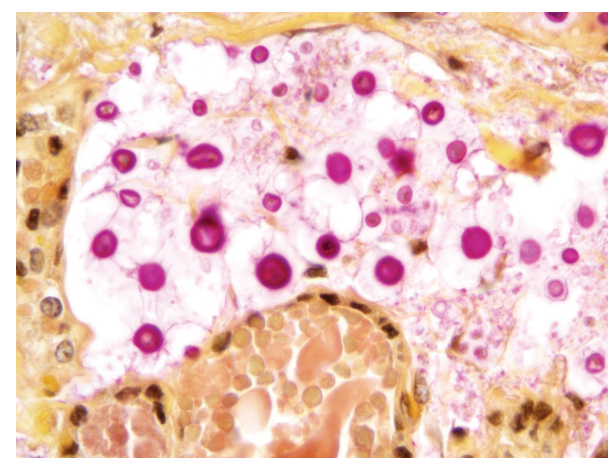

FIGURE 5: Microscopic section of the thyroid gland, mucin stain demonstrating thick capsule, and pleomorphic yeasts (1000x).

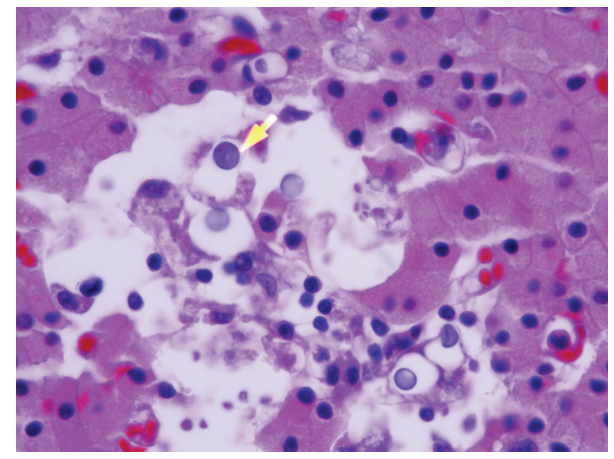

Figure 6: Microscopic section of the parathyroid gland showing Cryptococcus (yellow arrow). H\&E (1000x).

Review of patient's data showed that abnormal pathological findings were found entirely in patients with ongoing illicit drug use.

The histological findings in control patients revealed cytological appearances consistent with benign thyroid nodular disease in $8 \%$ of control patients, interstitial fibrosis in $2.6 \%$, lymphocytic thyroiditis in $2.6 \%$, cryptococcal infection in $1.3 \%$, papillary carcinoma in $1.3 \%$, and mycobacterial tuberculosis in $1.3 \%$ of the control specimens (Table 3 ). The histological appearance of parathyroid glands from the control group did differ from the HIV group with 72 control patients (96\%) showing normal histological appearance of the parathyroids as opposed $69 \mathrm{HIV}$-infected patients $(67.6 \%)$ (Table 2).

\section{Discussion}

HIV infection and antiretroviral therapy can induce endocrine dysfunction. Patients with AIDS have increased prevalence of nonthyroidal illness, hypothyroidism, and abnormal serum parathyroid hormone (PTH) and serum calcium levels $[4,5]$. These alterations in thyroid hormones and calcium homeostasis are rarely the result of a direct infection or infiltration of the thyroid and parathyroid glands. Although subclinical hypothyroidism has been recognized as more prevalent among HIV-infected individuals, it does not appear to have an autoimmune basis [6]. Graves's disease

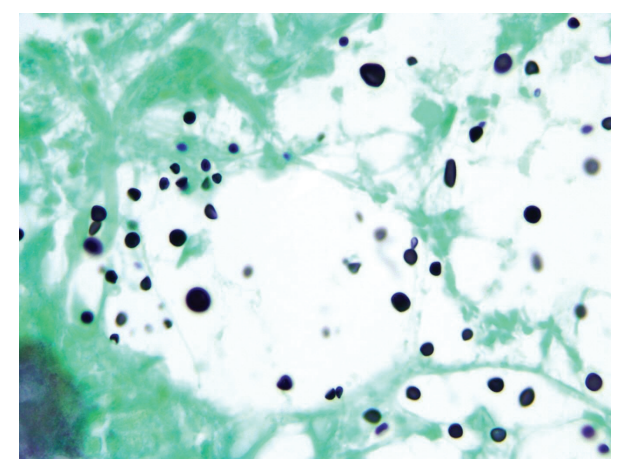

FIGURE 7: Microscopic section of the parathyroid gland, silver stain highlighting Cryptococcus with occasional narrow based budding (1000x).

subsequent to immune restoration due to HAART has been described and unlike the common infection-related immune reconstitution syndromes, it is usually diagnosed 12-36 months after HAART initiation [7]. Two studies from South America have described pathological changes in the thyroid gland in AIDS patients [8,9]. However, no investigator has reported the histopathology of parathyroid glands in Human Immunodeficiency Virus (HIV) patients. This study represents the first detailed report of thyroid and parathyroid gland abnormalities in a HIV-infected African-American population in the United States.

Ethnicity-related differences in organ systems involvement in HIV patients have been described previously by Morgello et al. with cachexia, renal, cardiac and splenic involvement more frequent in blacks than in whites and/or Hispanic individuals [10]. Additionally, Mycobacterium avium-intracellulare (MAI) infection is also more commonly seen in blacks than in whites and/or Hispanic individuals [11]. However the exact explanation for these discrepancies is not clear.

Our findings are strikingly different from what have been published so far in terms of the frequency of thyroid involvement in HIV.

Basílio-De-Oliveira from Brazil reviewed autopsy cases of 100 AIDS patients [8]. The study included 72 white patients. Compared to our findings, thyroid involvement by infectious processes was significant. Mycobacterium tuberculosis infection of the thyroid gland was found in $23 \%$ of patients and cytomegalovirus (CMV) in 17\%. Neoplastic involvement of the thyroid was also higher in frequency with Kaposi sarcoma (2\%) and occult papillary carcinoma (4\%) seen in patients. Histopathological lesions consisted mainly of interstitial fibrosis with follicular atrophy. Lima et al. studied forty-seven thyroids obtained at autopsy from 38 men and 9 women with AIDS in Brazil [9]. However, the ethnicity of the sample population was not documented. In contrast to our results, they identified greater frequency of infectious pathogens (14 cases, 29.7\%) with five cases of mycobacterial infection (10.6\%), four cases of histoplasmosis and cryptococcosis, and finally one case of paracoccidioidomycosis [11]. Their results were concordant with BasílioDe-Oliveira in regard to Mycobacterium infection being 
TABLE 5: Frequency of opportunistic infections in HIV infected individuals.

\begin{tabular}{lcc}
\hline $\begin{array}{l}\text { Number of } \\
\text { opportunistic } \\
\text { infections }\end{array}$ & $\begin{array}{c}\text { Patients with } \\
\text { normal thyroid } \\
\text { glands } \\
n=89(\%)\end{array}$ & $\begin{array}{c}\text { Patients with } \\
\text { abnormal thyroid } \\
\text { glands } \\
n=13(\%)\end{array}$ \\
\hline 0 & $30(33.7 \%)$ & $1(7.7 \%)$ \\
1 & $27(30.3 \%)$ & $6(46.1 \%)$ \\
2 & $21(23.5 \%)$ & $4(30.7 \%)$ \\
3 & $7(7.8 \%)$ & $2(15.3 \%)$ \\
4 & $2(2.2 \%)$ & 0 \\
5 & $1(1.1 \%)$ & 0 \\
$6^{*}$ & $1(1.1 \%)$ & 0 \\
\hline
\end{tabular}

${ }^{*}$ MAC, cytomegalovirus, Cryptococcus, Candida, Pneumocystis jiroveci, and Herpes.

the most frequently detected agent. This may be due to the higher prevalence of mycobacteria in AIDS patients in Brazil $[11,12]$.

In postmortem examinations of these patients, thyroid pathology was common affecting 29 patients (61.3\%), with nonspecific focal chronic inflammation affecting 14 cases (48.2\%), colloid goiter in 5 cases (17.2\%), and lipomatosis in 4 cases $(13.7 \%)$. Lipomatosis was associated with atrophy (1 case), hyperplastic nodule (1 case), and histoplasmosis (1 case) [9].

In our study, the frequency of infectious etiology affecting the thyroid gland was limited to $2.9 \%$ (3 cases).There was only one case of cytomegalovirus (CMV), Cryptococcus, and tuberculosis. All our cases inclined to have occurred in the context of a widely 5 disseminated disease.

Several cases have been previously reported also as part of multiple organ involvement either antemortem or at autopsy [13-17]. In our series, some patients presented with multiple coexisting opportunistic infections. About $45 \%$ of patients in the HIV group with thyroid pathology had more than 2 opportunistic infections as opposed to $35 \%$ in the subgroup of HIV patients with normal thyroid histopathology (Table 5). Based on the limited number of patients, we cannot postulate a possible association between opportunistic infections and the occurrence of thyroid abnormalities.

While in previous case reports, Pneumocystis jiroveci has been a prominent cause of thyroiditis in HIV patients [18-21], particularly in patients on aerosolized pentamidine $[22,23]$, we did not identify this microorganism in any of our patients. This may be due to the fact that many patients presented to our hospital with symptoms suggestive of Pneumocystis jiroveci pneumonia and were treated promptly with trimethoprim-sulfamethoxazole leading to absence of histological evidence of this microorganism at autopsy.

This observation is consistent with other studies showing that after "curing" patients of their pneumocystis infections, biopsy specimens usually lack evidence of residual disease $[24,25]$.

Our most common finding was interstitial fibrosis seen in 5 of the 12 microscopic cases. Contempre et al. have linked thyroid fibrosis to transforming growth factor beta (TGFbeta) in which follicular cell necrosis occurs first followed by thyroid fibrosis in the setting of selenium deficiency [26]. Similarly, interstitial fibrosis of the thyroid gland in our series could represent the histologic sequelae of previous inflammatory or infectious assaults coupled with an impaired tissue repair due to the underlying immunosuppression. In addition, Human Immunodeficiency Virus infection itself is associated with increased levels of transforming growth factor beta (TGF-beta) [27].

Of note, we identified two cases of thyroid hyperplasia which has been described as a normal response to alterations in the feedback mechanism of thyrotropin-releasing hormone and thyroid-stimulating hormone [28]. Additionally, it has been shown that HIV-1-infected inflammatory cells may release a mitogen protein (TAT) which enhances the production of growth factors including fibroblast growth factor (FGF-1 and FGF-2) and transforming growth factorbeta [29]. These fibroblast growth factors appear to be involved in the pathogenesis of thyroid hyperplasia [30].

Neoplastic involvement of the thyroid gland was present in one case. Kaposi sarcoma is the most common malignancy associated with HIV infection [31]. Kaposi sarcoma of the thyroid is uncommon, described only in the context of a widespread metastasis [32]. Its pathogenesis involves immunodeficiency, oncogenic DNA viruses, and the HIV-1 protein Tat [33].

Little is known about the relative contribution of illicit drugs use to the thyroid histopathology in HIV-infected populations. Our study suggests that ongoing drug use may impact thyroid tissue in HIV patients.

There is scant literature about the histopathology of the parathyroid glands in HIV patients. We identified parathyroid hyperplasia as the most common histological process (Table 4). The histologic appearance of parathyroid hyperplasia was hypercellularity with heterogenous cell proliferation but predominantly chief cells associated with reduced stromal fat and involving more than one gland.

This finding could be reflective of the secondary hyperparathyroidism resulting from the high prevalence of vitamin $\mathrm{D}$ deficiency in African American [34] in general and also specifically HIV-infected individuals $[35,36]$, although we do not have vitamin D levels in any of these patients. Both parathyroid and nodular oncocytic hyperplasia have been described as a feature of secondary hyperparathyroidism [37]. In the HIV population in particular, this process can also result from decreased serum calcium secondary to impairment in renal function, nutritional status, and chronic malabsorption.

Of note, a decrease of parathyroid hormone (PTH) level has also been previously reported in human immunodeficiency virus (HIV)-infected patients [38]. The mechanism might be related to antibodies against parathyroid cells. Using anti-Leu3a, a monoclonal antibody recognizing CD4, HIVpositive patients have been found to express CD4 molecule at the surface of parathyroid gland cells, indicating the possibility of either functional inhibition by anti-CD4 antibodies or direct infection by HIV [39].

In addition, current evidence indicates that HIV-infected persons have micronutrient deficiencies [40]. Therefore, the question of whether parathyroid hyperplasia could be related 
to possible micronutrient deficiency such as iodine deficiency remains to be established in HIV-infected subjects. Further research is needed to elucidate the role of micronutrient deficiencies on parathyroid pathology in HIV-infected subjects.

Our study findings must be interpreted in light of several limitations. First, our findings stem from a retrospective review of general autopsies in HIV-infected African American patients; hence, the small number of histologic sections might have influenced the microscopic findings recorded.

Larger studies focusing on thyroid and parathyroid are required to establish the prevalence of our findings.

Second, we were unable to analyze the thyroid function tests and the autoimmune status of our sample. One could argue that interstitial fibrosis is fairly non-specific and further prospective studies correlating histopathological findings with thyroid serologies for a better assessment of thyroid pathology in HIV African American population are needed.

\section{Conclusion}

We conclude that thyroid and parathyroid abnormalities are uncommon findings in the HIV-infected African American population. The most common characteristics of histopathology seen in the thyroid and parathyroid glands in these patients include interstitial fibrosis and parathyroid hyperplasia, respectively.

\section{Abbreviations}

HIV: $\quad$ Human Immunodeficiency Virus

AIDS: $\quad$ Acquired Immune Deficiency Syndrome

HAART: Highly Active Antiretroviral Treatment

BMI: $\quad$ Body mass index

CMV: $\quad$ Cytomegalovirus

MAI: $\quad$ Mycobacterium avium-intracellulare

PTH: Parathyroid hormone

MAC: $\quad$ Mycobacterium avium complex

TGF-beta: Transforming growth factor beta

FGF: $\quad$ Fibroblast growth factor

H\&E: Hematoxylin and eosin stain.

\section{Conflict of Interests}

The authors have no conflict of interests to disclose.

\section{References}

[1] A. Danoff, "HIV and the thyroid-what every practicing endocrinologist needs to know," Nature Clinical Practice Endocrinology and Metabolism, vol. 2, no. 11, pp. 602-603, 2006.

[2] K. Samaras, "Metabolic consequences and therapeutic options in highly active antiretroviral therapy in human immunodeficiency virus-1 infection," Journal of Antimicrobial Chemotherapy, vol. 61, no. 2, pp. 238-245, 2008.

[3] D. E. Sellmeyer and C. Grunfeld, "Endocrine and metabolic disturbances in Human Immunodeficiency Virus infection and the Acquired Immune Deficiency Syndrome," Endocrine Reviews, vol. 17, no. 5, pp. 518-532, 1996.
[4] S. Beltran, F. Lescure, R. Desailloud et al., "Increased prevalence of hypothyroidism among human immunodeficiency virusinfected patients: a need for screening," Clinical Infectious Diseases, vol. 37, no. 4, pp. 579-583, 2003.

[5] E. W. Kuehn, H. J. Anders, J. R. Bogner, J. Obermaier, F. D. Goebel, and D. Schlöndorff, "Hypocalcaemia in HIV infection and AIDS," Journal of Internal Medicine, vol. 245, no. 1, pp. 6973, 1999.

[6] S. Beltran, F.-X. Lescure, I. El Esper, J.-L. Schmit, and R. Desailloud, "Subclinical hypothyroidism in HIV-infected patients is not an autoimmune disease," Hormone Research, vol. 66, no. 1, pp. 21-26, 2006.

[7] C. J. Hoffmann and T. T. Brown, "Thyroid function abnormalities in HIV-infected patients," Clinical Infectious Diseases, vol. 45, no. 4, pp. 488-494, 2007.

[8] C. A. Basílio-De-Oliveira, "Infectious and neoplastic disorders of the thyroid in AIDS patients: an autopsy study," The Brazilian Journal of Infectious Diseases, vol. 4, no. 2, pp. 67-75, 2000.

[9] M. A. Lima, L. L. L. Freitas, C. Montandon, D. C. Filho, and M. L. Silva-Vergara, "The thyroid in acquired immunodeficiency syndrome," Endocrine Pathology, vol. 9, no. 3, pp. 217-223, 1998.

[10] S. Morgello, R. Mahboob, T. Yakoushina, S. Khan, and K. Hague, "Autopsy findings in a human immunodeficiency virus-infected population over 2 decades: influences of gender, ethnicity, risk factors, and time," Archives of Pathology and Laboratory Medicine, vol. 126, no. 2, pp. 182-190, 2002.

[11] M. de C Ramos, M. Jacques De Moraes, A. L. Calusni, G. N. Roscani, and E. Picolli Alves, "A retrospective bacteriological study of mycobacterial infections in patients with acquired immune deficiency syndrome (AIDS)," The Brazilian Journal of Infectious Diseases, vol. 4, no. 2, pp. 86-90, 2000.

[12] S. M. Nakatani, I. J. T. Messias-Reason, M. Burger, and C. A. Cunha, "Prevalence of Mycobacterium avium and Mycobacterium tuberculosis in blood cultures of Brazilian AIDS patients after introduction of highly active retroviral therapy," Brazilian Journal of Infectious Diseases, vol. 9, no. 6, pp. 459-463, 2005.

[13] A. H. Szporn, S. Tepper, and C. W. Watson, "Disseminated cryptococcosis presenting as thyroiditis. Fine needle aspiration and autopsy findings," Acta Cytologica, vol. 29, no. 3, pp. 449453, 1985.

[14] L. Z. Goldani, A. P. Zavascki, and A. L. Maia, "Fungal thyroiditis: an overview," Mycopathologia, vol. 161, no. 3, pp. 129-139, 2006.

[15] A. M. Avram, C. A. Sturm, C. W. Michael, J. C. Sisson, and C. A. Jaffe, "Cryptococcal thyroiditis and hyperthyroidism," Thyroid, vol. 14, no. 6, pp. 471-474, 2004.

[16] T. S. Frank, V. A. LiVolsi, and A. M. Connor, "Cytomegalovirus infection of the thyroid in immunocompromised adults," Yale Journal of Biology and Medicine, vol. 60, no. 1, pp. 1-8, 1987.

[17] X. Zhang, D. El-Sahrigy, A. Elhosseiny, and M. R. Melamed, "Simultaneous cytomegalovirus infection and kaposi's sarcoma of the thyroid diagnosed by fine needle aspiration in an aids patient: a case report and first cytologic description of the two entities occurring together," Acta Cytologica, vol. 47, no. 4, pp. 645-648, 2003.

[18] R. Battan, P. Mariuz, M. C. Raviglione, M. T. Sabatini, M. P. Mullen, and L. Poretsky, "Pneumocystis carinii infection of the thyroid in a hypothyroid patient with AIDS: diagnosis by fine needle aspiration biopsy," Journal of Clinical Endocrinology and Metabolism, vol. 72, no. 3, pp. 724-726, 1991.

[19] M. McCarty, R. Coker, and E. Claydon, "Case report: Disseminated Pneumocystis carinii infection in a patient with 
the acquired immune deficiency syndrome causing thyroid gland calcification and hypothyroidism," Clinical Radiology, vol. 45, no. 3, pp. 209-210, 1992.

[20] D. J. Drucker, D. Bailey, and L. Rotstein, "Thyroiditis as the presenting manifestation of disseminated extrapulmonary pneumocystis carinii infection," Journal of Clinical Endocrinology and Metabolism, vol. 71, no. 6, pp. 1663-1665, 1990.

[21] R. Guttler, P. A. Singer, S. G. Axline et al., "Pneumocystis carinii thyroiditis: report of three cases and review of the literature," Archives of Internal Medicine, vol. 153, no. 3, pp. 393-396, 1993.

[22] M. V. Ragni, A. Dekker, F. R. DeRubertis et al., "Pneumocystis carinii infection presenting as necrotizing thyroiditis and hypothyroidism," American Journal of Clinical Pathology, vol. 95, no. 4, pp. 489-493, 1991.

[23] A. E. Walts and H. E. Pitchon, "Pneumocystis carinii in FNA of the thyroid," Diagnostic Cytopathology, vol. 7, no. 6, pp. 615-617, 1991.

[24] C. H. Hsiao, S. H. Huang, S. F. Huang et al., "Autopsy findings on patients with AIDS in Taiwan," Zhonghua Min Guo Wei Sheng Wu Ji Mian Yi Xue Za Zhi, vol. 30, no. 3, pp. 145-159, 1997.

[25] C. M. Reichert, T. J. O’Leary, and D. L. Levens, “Autopsy pathology in the acquired immune deficiency syndrome," American Journal of Pathology, vol. 112, no. 3, pp. 357-382, 1983.

[26] B. Contempre, O. Le Moine, J. E. Dumont, J.-F. Denef, and M. C. Many, "Selenium deficiency and thyroid fibrosis. A key role for macrophages and transforming growth factor $\beta$ (TGF- $\beta$ )," Molecular and Cellular Endocrinology, vol. 124, no. 1-2, pp. 7-15, 1996.

[27] S. Amarnath, L. Dong, J. Li, Y. Wu, and W. Chen, "Endogenous TGF- $\beta$ activation by reactive oxygen species is key to Foxp3 induction in TCR-stimulated and HIV-1-infected human CD4+CD25-T cells," Retrovirology, vol. 4, article 57, 2007.

[28] M. D. Perez-Montiel and S. Suster, “The spectrum of histologic changes in thyroid hyperplasia: a clinicopathologic study of 300 cases," Human Pathology, vol. 39, no. 7, pp. 1080-1087, 2008.

[29] S. R. Opalenik, J. T. Shin, J. N. Wehby, V. K. Mahesh, and J. A. Thompson, "The HIV-1 TAT protein induces the expression and extracellular appearance of acidic fibroblast growth factor," The Journal of Biological Chemistry, vol. 270, no. 29, pp. 17457-17467, 1995.

[30] S. D. Thompson, J. A. Franklyn, J. C. Watkinson, J. M. Verhaeg, M. C. Sheppard, and M. C. Eggo, "Fibroblast growth factors 1 and 2 and fibroblast growth factor receptor 1 are elevated in thyroid hyperplasia," Journal of Clinical Endocrinology and Metabolism, vol. 83, no. 4, pp. 1336-1341, 1998.

[31] Y. Aoki and G. Tosato, "Targeted inhibition of angiogenic factors in AIDS-related disorders," Current Drug Targets, vol. 3, no. 2, pp. 115-128, 2003.

[32] P. H. Krauth and J. F. Katz, "Kaposi's sarcoma involving the thyroid in a patient with AIDS," Clinical Nuclear Medicine, vol. 12, no. 11, pp. 848-849, 1987.

[33] G. Nunnari, J. A. Smith, and R. Daniel, "HIV-1 Tat and AIDSassociated cancer: targeting the cellular anti-cancer barrier?" Journal of Experimental and Clinical Cancer Research, vol. 27, no. 1, article 3, 2008.

[34] S. S. Harris, "Vitamin D and African Americans," Journal of Nutrition, vol. 136, no. 4, pp. 1126-1129, 2006.

[35] M. Rodríguez, B. Daniels, S. Gunawardene, and G. K. Robbins, "High frequency of vitamin D deficiency in ambulatory HIVPositive patients," AIDS Research and Human Retroviruses, vol. 25, no. 1, pp. 9-14, 2009.
[36] C. J. P. van den Bout-van den Beukel, L. Fievez, M. Michels et al., "Vitamin D deficiency among HIV type 1-infected individuals in the Netherlands: effects of antiretroviral therapy," AIDS Research and Human Retroviruses, vol. 24, no. 11, pp. 1375-1382, 2008.

[37] R. V. Lloyd, B. R. Douglas, and W. F. Young Jr., Endocrine Diseases, Atlas Nontumor Pathology First Series, vol. 1, pp. 7478, Armed Forces Institute of Pathology, Washington, DC, USA, 2002.

[38] P. Jaeger, S. Otto, R. F. Speck et al., "Altered parathyroid gland function in severely immunocompromised patients infected with human immunodeficiency virus," Journal of Clinical Endocrinology and Metabolism, vol. 79, no. 6, pp. 1701-1705, 1994.

[39] P. Hellman, A. Karlsson-Parra, L. Klareskog et al., "Expression and function of a CD4-like molecule in parathyroid tissue," Surgery, vol. 120, no. 6, pp. 985-992, 1996.

[40] P. K. Drain, R. Kupka, F. Mugusi, and W. W. Fawzi, "Micronutrients in HIV-positive persons receiving highly active antiretroviral therapy," American Journal of Clinical Nutrition, vol. 85, no. 2, pp. 333-345, 2007. 


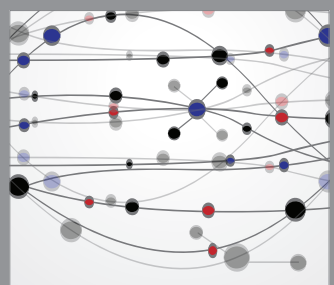

The Scientific World Journal
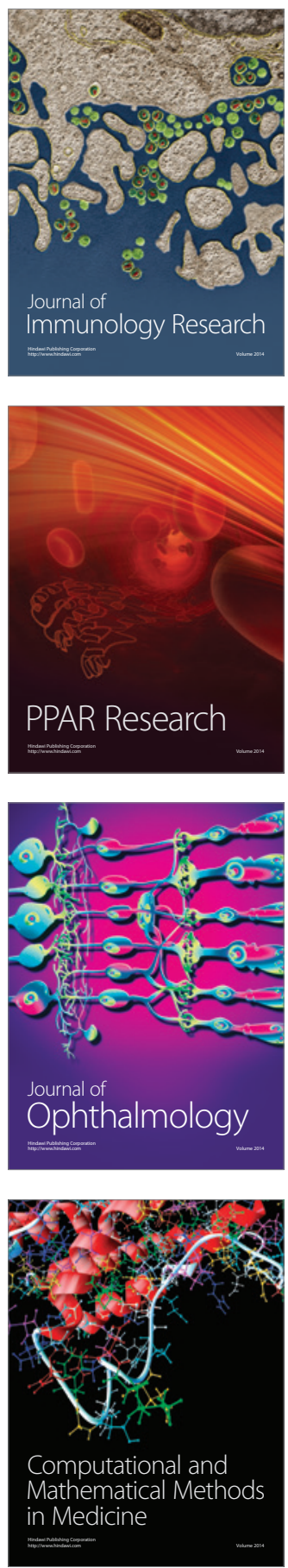

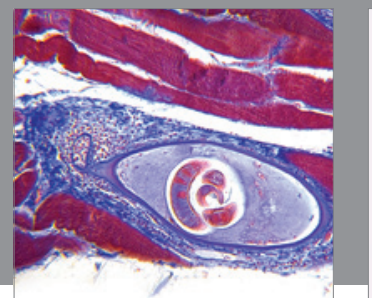

Gastroenterology

Research and Practice
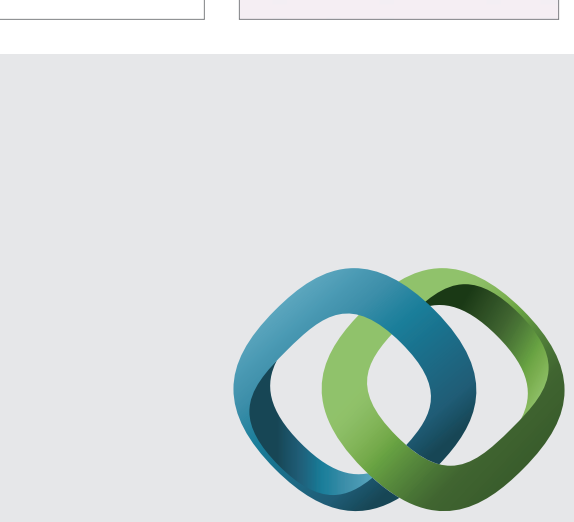

\section{Hindawi}

Submit your manuscripts at

http://www.hindawi.com
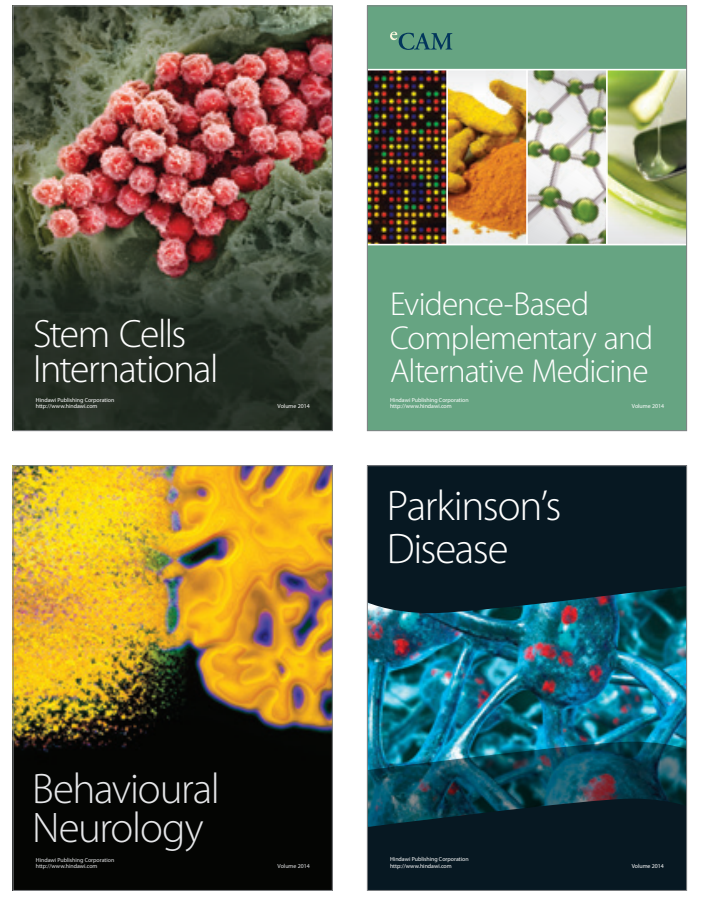
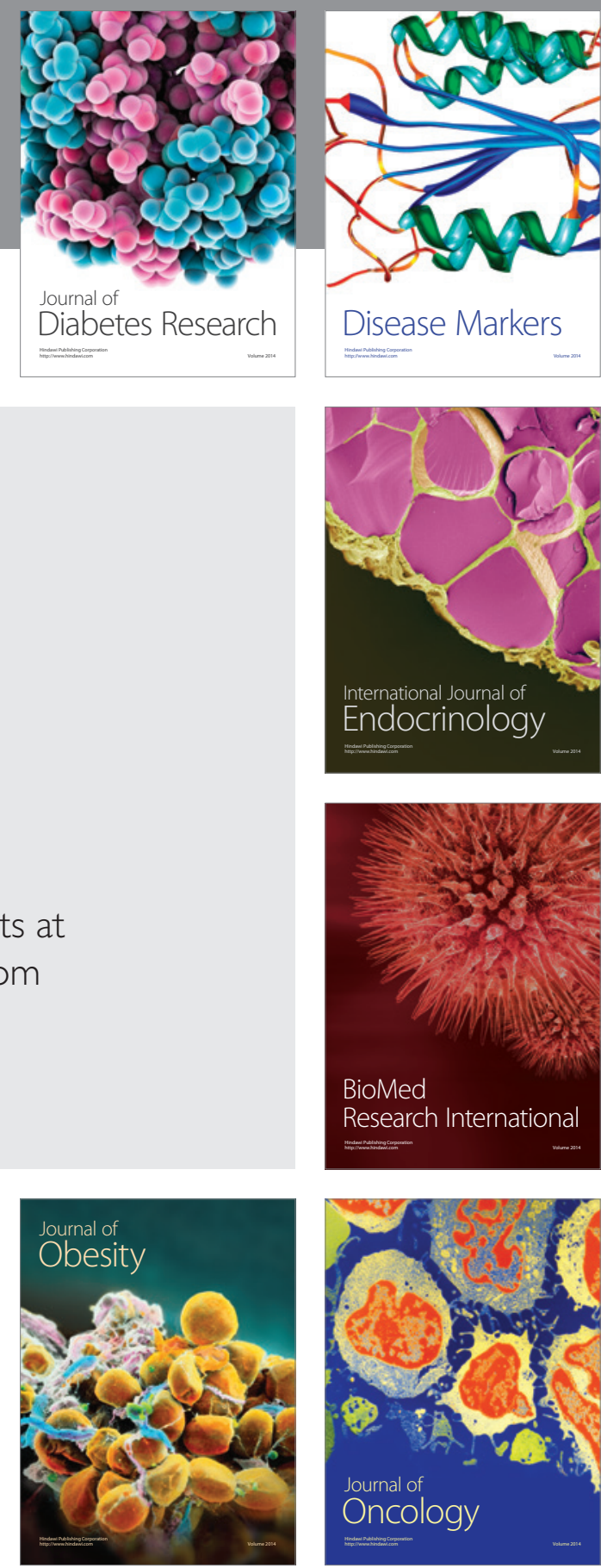

Disease Markers
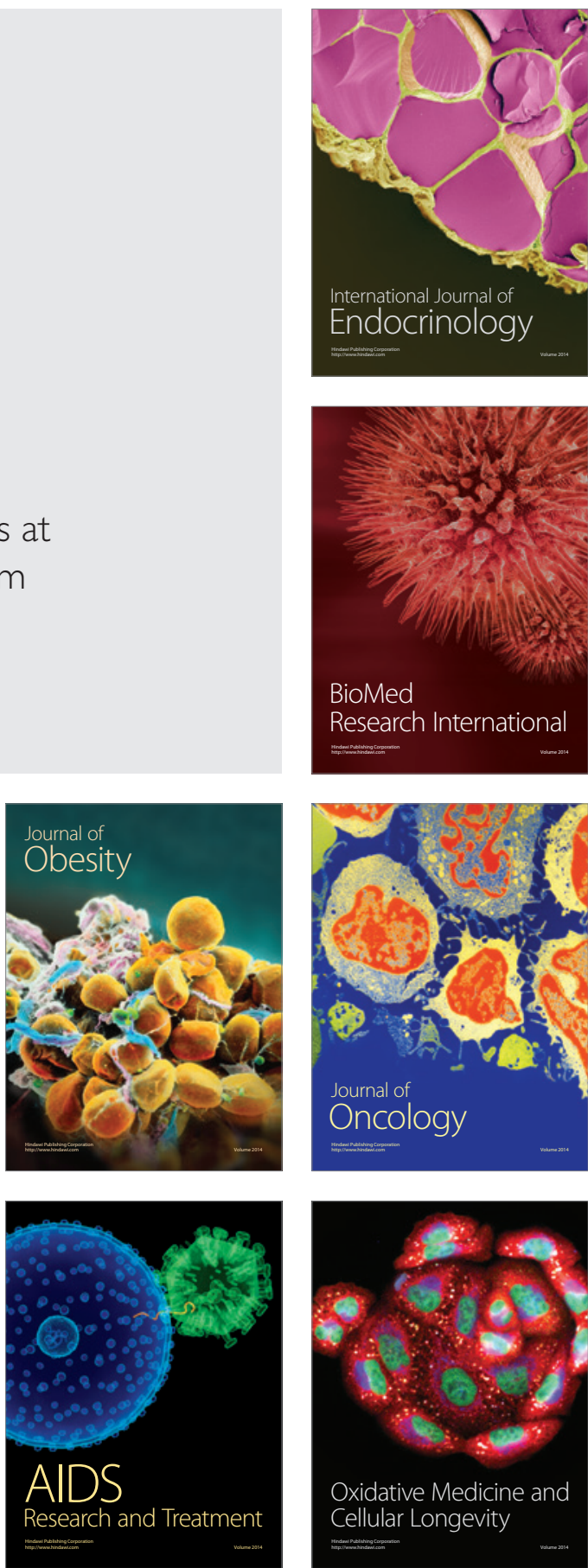